\title{
A pesquisa em jornalismo e as pesquisas sobre crianças e adolescentes
}

\author{
Cristina Pontes*
}

\begin{abstract}
RESUMO
O tratamento jornalistico de crianças e questões com ela relacionadas têm crescido nos últimos vinte anos, associados a mudanças no jornalismo e também a mudanças sociais. Este artigo revê alguns dos estudos sobre a noticiabilidade da infância, realizados em diferentes países, e dá conta das linhas das noticias sobre crianças num jornal português, de 1970 a 2000 . Defende que estas noticias ganham em ser entendidas à luz de uma perspectiva cultural, que tenha em conta as visões do mundo, as práticas, os formatos e as audiéncias do jornalismo, e termina apresentando os objectivos de um projecto de pesquisa em curso em Portugal, inspirado no trabalho da ANDI.
\end{abstract}

Palavras-chave: jornalismo, noticia, crianças, pesquisa, análise cultural

\section{ABSTRACT}

News on children and related issues has been grown since the 1980s, associated with social changes in journalism and in societies. This article reviews research on the ways children are presented in mainstream newspapers, from different countries, including a long-term analysis based on a Portuguese newspaper (1970-2000). This is the starting point to sustain that this coverage needs to be understood also through a cultural perspective, paying attention to the different visions, practices, formats and audiences promoted by journalism. The article concludes presenting the aims of a running project based on this cultural agenda as well as on ANDI work in Brazil and Latin America.

Key words: Journalism; News; Children; Research; Cultural Analysis

- Professar da Faculdade de Ciéncias Sociais e Humanas de Universidade Nova de Lisboa a Coordenadora do Projecto Crianças e Jovens nas Noticias, apoiado pela Fundaç̧ăo para a Ciência e Tecnologia (POCl/COM/60020/2004). 


\section{Introdução}

Muito da pesquisa acadêmica tem incidido apenas sobre uma parte do que constitui o jornalismo, tomando-a pelo todo, numa atenção sobretudo à construção noticiosa de figuras públicas de destaque e à sua intervenção em grandes temas ou momentos da vida social. Como escreve a investigadora norte-americana Barbie Zelizer, "o jornalismo tem sido sobretudo definido em termos de uma dimensão reduzida (e em decréscimo) de notícias - as hard news, e isto tem criado um desvio que impede os pesquisadores de incidirem sobre o jornalismo em todas as suas diferentes formas, dimensões e práticas (Zelizer, 2004: 6).

A atenção à pluralidade do jornalismo foi há muito destacada por Helen Hughes (1940), uma investigadora da tradição sociológica humanista da Escola de Chicago. Hughes considerava os jornais como habitáculos de diferentes ordens de discurso, incluindo o campo das notícias de interesse humano, capazes de interessar uma audiência vasta e diversificada. James Carey é hoje o principal rosto da perspectiva cultural sobre a comunicação. Num ensaio sobre jornalismo, de 1975, Carey sublinha que as noticias sâo mais do que informação, que o jornalismo é um "acto cultural", que a escrita jomalística é uma entre outras formas literárias, pelo seu trabalho de criação e de imaginação, esta numa dimensão claramente social.

Outro pesquisador norte-americano, Michael Schudson (2000) 8 destaca a importância da leitura cultural - a par da economia política e da sociologia das redacções - nos estudos sobre jornalismo, mas sublinha também a necessidade de enriquecer a pesquisa acentuando a dimensão histórica e comparada.

À escassez de estudos comparados associa-se a tendência para as análises se centrarem em tempos relativamente curtos, nos chamados "picos noticiosos". Esses focos temporais e espaciais demasiado estreitos podem tornar a pesquisa incapaz para dar conta dos enquadramentos históricos e das considerações culturais que enformam o discurso público, aspecto destacado por sua vez pela investigadora britânica Jenny Kitzinger, que acompanha há duas décadas o tratamento mediático de questões sociais como o abuso sexual de crianças e como os seus enquadramentos têm sido interpretados por parte das audiências (Kitzinger, 1999, 2004).

Notícias sobre temas e questões sociais podem constituir um campo de pesquisa que articula o jornalismo com esses enquadramentos históricos e considerações de "senso comum". É o caso de dimensões simbólicas, não expressas mas implícitas, nas formas de reportar sobre minorias sociais, como os imigrantes, as mulheres, os idosos, as crianças e jovens.

Encontramos nos estudos sobre a noticiabilidade de crianças indicadores que sublinham a sua relevância para a agenda da pesquisa sobre o que é notícia, as diferentes narrativas do jornalismo e as suas contingências. 
Percorremos de seguida alguns desses estudos, para introduzirmos, depois, questões suscitadas pela pesquisa longitudinal que realizamos sobre a cobertura jornalística de crianças (1970-2000), e que estamos a actualizar na imprensa portuguesa.

\section{Estudos sobre a noticiabilidade das crianças}

Os estudos sobre os modos como as crianças aparecem nas notícias de imprensa e de televisão são cscassos no panorama dos estudos da comunicação, comparados com a atenção que tem sido dada aos efeitos dos media e dos seus conteúdos sobre os mais novos, em particular centrada na questão da violência (ver, por exemplo, Carlsson U, Feilitzen Cv, eds. 1998). São estudos também relativamente recentes: numa pesquisa bibliográfica sobre o tratamento jornalístico de crianças e de questões com elas relacionadas, concluída em 2002, entre uma centena de títulos sobre o tema, sobretudo artigos, mais de $85 \%$ eram posterior a 1996 (Ponte, 2005).

A atenção a este tema não está dissociada da maior visibilidade às questões da infância, estimulada pela aprovação da Convenção dos Direitos da Criança, em 1989, que suscitou uma chamada de atenção pública para situações problemáticas que envolviam os membros mais novos da sociedade. O caso do Brasil, e da implantaçâo da ANDI, é paradigmático da mobilização social em torno da defesa dos direitos das crianças e adolescentes e da atenção $e$ intervenção junto aos grandes jornais para uma cobertura em alternativa à mera "denúncia de factos". O trabalho continuado da ANDI permite salientar os pontos e os temas onde as rotinas profissionais encontraram mais resistência a serem substituidas por novas práticas, nas formas de recolher e tratar a informação e nas iniciativas de agenda. A constatação e a comparação dessas frentes de resistência e de abertura são, certamente, um excelente veículo para pensar a notícia e o jornalismo. A colecção Midia e Mobilização Social, tornando públicas essas dificuldades e mudanças, acompanhadas de alternativas, é um contributo para uma maior tomada de consciência social do que é a notícia.

Entre os estudos sobre o tratamento das crianças nos media noticiosos, destaco pela sua dimensão comparada o trabalho coordenado por Anura Goonasekera (2001), do Asian Mass Communication Research and Information Centre, que envolveu 13 países asiáticos, em 1999. Dez anos depois da assinatura da Convenção, investigadores do Bangladesh, China, Filipinas, Índia, Indonésia, Japão, Malásia, Nepal, Paquistão, Singapura, Srilanka, Tailândia e Vietnamc analisaram o conteúdo noticioso dos principais jornais e canais televisivos do país e interrogaram os seus jornalistas sobre a atenção às problemáticas das crianças e da infância.

Deste estudo, são relevantes as assimctrias, cntrc países mais pobres e mais longe da modernidade, onde as crianças continuam a ser apreciadas 
por valores essencialmente econômicos e onde a infância ainda parece não se ter constituído como entidade nacional e investimento no futuro, e paises industrializados, onde o potencial afectivo e simbólico é capitalizado como valor jornalistico, a par da mercantilização da infância e dos sentimentos que suscita.

Nos Estados Unidos, a pesquisa realizada em Departamentos de Jornalismo e de Ciência Política deu conta da ascensão de notícias sobre crianças a partir das décadas de 1980 e 1990. O fenômeno é inserido no contexto das mudanças no sentido do comercialismo e do "jornal total" (Hallin, 1996), que atinge os media norte-americanos, combinando critérios de noticiabilidade com orientações de marketing na captação de novos leitores, nomeadamente femininos. A presença freqüente de crianças no noticiário internacional é, por sua vez, enquadrada no contexto geopolítico das mudanças após o final da Guerra-fria. Escreve a pesquisa Susan Moeller, da Ciência Política (2002: 38-39):

"A doutrina de que os Estados Unidos deviam salvar o mundo (digamos, do comunismo) deu lugar à opinião de que os americanos deveriam salvar as crianças da fome ou de maus-tratos. Tornou-se necessária uma nova gramática ou sintaxe da discussão pública, para acompanhar esses objectivos diplomáticos, orientações ou objectivos programáticos, e as crianças tornaram-se parte dessa linguagem. A sua invocação confere calor a um argumento favorável (ou desfavorável) a uma medida pública e sustenta a orientação moral do debate."

A investigação comparada conduzida por Dale Kunkel (1999), da Universidade de Santa Barbara, Califórnia, sobre as notícias sobre crianças apresentadas em grandes jornais e canais de televisão norte-americanos, durante um mês, em 1993 e cinco anos mais tarde, em 1998, ilustra essa subida notória do número de peças em ambos os meios. Na imprensa, a subida foi acompanhada pela estabilidade nas formas de reportar esse tema: localização sobretudo em primeira página do jornal, e nas secçổes Local e Estilos de Vida; predominio do texto curto e das vozes inquiridas, sobretudo especialistas e fontes institucionais.

A distribuição temática das notícias em 1993 e 1998 dá conta da descida notória de Crime/Violência (de $40 \%$ das peças de 1993, ano em que vários grandes jornais levaram a cabo "cruzadas contra a criminalidade", para $23 \%$ em 1998), subida nos temas de Saúde (de 11 para 19\%) e Família (de 11 para $21 \%$ ), tendo a Educação permanecido relativamente estável (de 25 para 23\%). Assinala-se assim o peso de coberturas noticiosas de Questões Culturais ( $9 \%$ nos dois momentos), sobre conteúdos como moda, espectáculos, televisão. Por outro lado, registre-se a baixa presença relativa da Economia (de 4 para 6\%). 
O reconhecimento da atenção a crianças por parte dos media noticiosos norte-americanos, freqüentemente acompanhado por um forte sensacionalismo noticioso, fez com que Universidades iniciassem programas de formação especializada para essa cobertura, como Covering the Youth Beat, da Universidade de Columbia, Nova Iorque, em curso desde 1992. Outras pesquisas, menos sistemáticas e quantitativas mas de grande alcance cultural, têm dado contributos para pensar os valores profundos activados na cobertura jornalística dos mais novos. No contexto europeu, é o caso da atenção por parte de investigadores britânicos à cobertura jornalística desmesurada de crimes cometidos por crianças (James e Jenks, 1996) ou de abuso sexual de crianças (Kitzinger, 1999; 2004; Skidmore, 1998). É o caso também da atenção ao recurso simbólico à criança no discurso político parlamentar e eleitoral, estudado pelas investigadoras alemãs Doris BuhlerNiederberger (1997 e 1999) e Beatrice Hungerland (1997). A exclusão do valor econômico da criança nas sociedades mais ricas, do Ocidente, fez elevar o valor emocional até ao nível do sagrado, consubstanciando uma criança tipo cujo reconhecimento se universalizou e que tem sido reforçado por agências públicas. Escrevem as autoras (1997:8):

"A sua imagem procura ser natural, e deve ser cuidadosamente preservada. Qualquer violação desta natureza irá inevitavelmente pôr em perigo não só a criança como a sociedade. A criança tipo é ainda o guia dos debates públicos comuns. Exige ser aplicada a todas as crianças, independentemente da idade, sexo, posição social ou contexto cultural."

Por outro lado, e ao contrário do que acontece neste momento no Brasil e noutros países da América Latina, no contexto europeu a atenção às problemáticas da infância tem encontrado algum desinteresse na classe jornalistica. Mike Jempson (2003), director do observatório Mediawise, contrapondo aos resultados da ANDI, sublinha que muitos jornalistas dos grandes órgãos de informação europeus se manifestam cépticos quanto ao valor de prestarem atenção às necessidades das crianças.

Este relativo desinteresse não pode ser desligado do olhar político e cultural sobre os direitos das crianças na Europa. A habitual consideração sobre o bem-estar adquirido das crianças dos paises mais ricos subestima problemas sociais que as envolvem, como a discriminação, o abandono, a pobreza, o abuso ou o tráfico sexual, e que não têm cessado de crescer. 


\section{Portugal: Crianças em noticia (1970-2000)}

Uma pesquisa diacrônica apreciou todas as notícias sobre crianças com menos de 14 anos, publicadas em 1970, 1975, 1980, 1985, 1990, $1995 \mathrm{e}$ 2000 pelo Diário de Notícias (DN), um jornal de referência com um forte carácter institucional (Ponte, 2005). O objectivo era dar conta da construção jornalística da infầncia, e o que está a ela simbolicamente associado: fragilidade, dependência, inocência.

Os 30 anos abrangidos cobriram diferentes contextos da sociedade portuguesa e da imprensa: políticos, econômicos, sociais e culturais. $\mathrm{Na}$ redacção, encontramos em 1970 a censura em tempos de ditadura política; um jornalismo militante em 1975, no periodo revolucionário que se seguiu à sua queda da ditadura; o jornal estatizado e parte do sector público da comunicação social, na década de 1980; o jornal privatizado e pertença de um dos principais grupos privados de comunicação, na década seguinte.

De modo resumido, o que nos dizem as notícias sobre crianças? Em 1970 , sob censura, $45 \%$ das 661 matérias (o valor mais elevado, entre todos os anos estudados) davam conta de acidentes domésticos onde morriam ou ficavam gravemente feridas crianças de familias pobres, descritas como desditosas ou vítimas do destino. Em 1975, encontrou-se o menor número de matérias sobre crianças (252), sobretudo noticiadas como alvo da iniciativa de comissões de moradores e de trabalhadores, nas ocupações de edificios

12 para instalação de infantários populares, a par de referências à criança como homem novo. Nos anos 80 , cuidados de saúde e outras necessidades básicas são os principais temas, mas colocados nos espaços dos Suplementos para Mulheres e de Educação. Nos anos 90, a agenda mostra a emergência de temas como a violência sexual/pedofilia, consumos, actos de delinquiência.

Em 2000, a comparação com outro jornal de referência português, o Público, mostra uma variação percentual mínima entre os dois jornais nos grandes temas tratados, ainda que na maioria das vezes os eventos concretos noticiados não sejam coincidentes.

O DN apresenta então 660 matérias e $\circ$ Público, 561. As categorias principais coincidem nos dois jornais: 1) Educação; 2) Criança disputada (notícias sobre polêmicas sobre o que constitui o "melhor interesse para a criança" em matérias de decisão legal; para este valor elevado contribuiu a grande atenção que os dois jornais deram ao caso Elián Gonzalez, a criança cubana cuja custódia era reivindicada pelo pai e pelos familiares em Miami); 3) Políticas de proteç̧ão e assistência. Nos tópicos seguintes aparecem Abandonos e delinqüência na infância, em quarto e quinto lugar, no Diário de Noticias, enquanto notícias de acidentes e de violência sexual/pedofilia ocupavam essas posições no Público. Com excepção da Educação (16\% no Público, $11,5 \%$ no Diário de Noticias devido à existência de uma página diária de Educação no Público), as diferenças entre as categorias são 
inferiores a I ponto percentual. Uma vez que os eventos que reportavam não coincidiam na maioria dos casos, podemos ler esta similitude como um imaginário profissional partilhado sobre o que é relevante ou secundário em termos de noticiabilidade. Questões associadas à economia, como a pobreza e o trabalho infantil, têm também aqui pouca expressão, como o que foi encontrado nos estudos de Kunkel e de Goonasekera.

Em 2000, maioria dos conteúdos noticiosos provinha do território nacional, com a excepções da criança disputada e da violência sexual/pedofilia, situação que se irá alterar dada a grande visibilidade actual à questão do abuso sexual de crianças na sequêencia do Caso Casa Pia, actualmente em processo de julgamento e que envolveu figuras públicas da política e do espectáculo.

Essc cstudo de 30 anos deu conta de linhas de continuidade e de mudança sobre o que é notícia. A um primeiro olhar, são as mudanças que parecem mais visiveis, agregadas a transformações na própria sociedade, associadas a novos temas e novas fontes de informação. Contudo, o estudo mostrou-o, este dinamismo não significou o desaparecimento de temas perenes das agendas (como abandono e maus tratos, entre eles os acidentes), acontecimentos trabalhados muito mais como sucessão de eventos de série, do que pela sua interpelação pelo lado do social. Também conservador é o domínio de fontes oficiais e (algumas) fontes especializadas.

Há implicita mas incontornável também uma orientação estável das questões da infância para as mulheres (mães, profissionais de educação), para leitores no feminino. Por contraponto, registamos a escassez de discursos a partir da economia, da política, do direito, das ciências sociais. A reduzida atenção aos problemas dos mais novos nas sociedades contemporâneas teve como tradução, nos tempos mais recentes, em que este grupo social começou a ter visibilidade pública e politica e onde surgiram novas fontes de conhecimento e investigação, uma focagem na criança aluno, na criança da familia, em forma crescente na criança em risco, ameaçada pelos novos consumos, pela insegurança (onde cresce o medo do vizinho do lado como potencial pedófilo), pelos perigos da televisão ou da Internet que operam dentro de casa. Os imaginários de experiência traduzidos para notícia mostram assim uma construção restrita deste grupo. A esfera doméstica e a responsabilidade individual das famílias predomina sobre a esfera pública e a responsabilidade social do Estado.

A análise diacrônica permitiu também assinalar mudanças notórias nas formas da notícia, decorrentes de orientações editoriais, de dispositivos organizacionais e perfis profissionais de jornalistas que variaram significativamentc. Há diferenças abissais entre as noticias dos anos $70,80 \mathrm{e}$ 90 , naquilo que reportam e nos estilos textuais como o fazem. Contudo, a par desta mudança, destacamos nestas notícias envolvendo crianças uma estabilidade que (porventura) se acentua por contraste com outras coberturas 
sociais: predomínio do relato ligeiro e breve, escassez de comentário, quase ausência de jornalismo de investigação. Pensamos poder assim afirmar que a cobertura jornalística da infância evidenciada na análise diacrônica de 30 anos foi pautada pela escassez de dispositivos de racionalização, por contraste com uma intensa presença de registos únicos de fontes oficiais.

Outra marca destes 30 anos é a recorrência do uso de estruturas textuais e de enquadramentos de fait-divers, em textos curtos e pré-formatados, a redução dos eventos a histórias de interesse humano ou ao puro registo despojado de contexto. Se o melodrama é hoje mais controlado na sua forma textual, por contraste com 1970, acentuou-se em 2000 a configuração dos eventos como sucessão e somatório de casos singulares, com personagens planas e moral implícita de que esta parece ser a ordem natural das coisas.

Estáveis foram também os enquadramentos da infância traçados pela pena dos próprios profissionais em espaços híbridos de informaçãoentretenimento. Encontramos por vezes a fusão entre a voz do jornalista e a voz popular na descrição poética da infância como tempo de pureza, de inocência e de despreocupação, acompanhada por vezes pela nostalgia de um passado perdido ou de uma 'idade de ouro' que já não se verifica. Estes textos do jornalista não como relator mas como porta-voz do senso comum estão no jornal, ocupam espaço e que por muito marginais que se afigurem nos estudos sociológicos do jornalismo tem sentido serem interrogados sobre o seu porquê.

14 Nas construçð̋es de criança deste jornal de referência encontramos sem esforço a criança como líder simbólico das vítimas. Encontramos, lado a lado, a nostalgia da infância perdida, ilustrada pela ideia de que "as crianças já não são o que eram", e o romantismo de um ideal universal da infância como "tempo de inocência e de felicidade". Também lado a lado, encontramos a criança dotada, amada, consagrada, sobretudo a nossa criança, e a criança hedonista, a outra, das margens do social e em ascensão quantitativa nos noticiários nos últimos anos. Encontramos com freqüência a criança aluno com freqüência construída como sujeito ignorante e sem voz. Encontramos sobretudo a criança tipo de que fala Buhler-Niederberger e poucas crianças com infâncias híbridas e dinâmicas, com autonomia, desdobramento de actividades, saberes e conhecimentos.

Destacamos ainda escolhas nos dispositivos de enquadramento de ressonâncias culturais profundas e tradutoras de grandes consensos naturalizados: a mulher mãe é central, construída como figura da atenção e do desvelo a quem se dão conselhos, ou como a outra, figura renegada e contra natura, que abandona ou rejeita a sua cria, enquanto o pai tirano é figura quase ausente. Nesta cobertura longitudinal, predominou pois o valor emocional dos mais novos sobre o seu valor político no sentido de pessoas com direitos, como a legislação internacional consagra há décadas. Como noutros campos de aparente proximidade afectiva, não é difícil encontrar a 
idéia corrente de que as crianças dão boas imagens e boas histórias de interesse humano e de que não exigem grande especialidade para se falar delas.

\section{Pesquisa cultural e notícias sobre crianças: uma agenda em várias frentes}

Um dos traços que ressalta deste estudo de 30 anos de notícias sobre crianças foi exactamente dar conta da diversidade do que constitui o jornalismo, a necessidade de atenção às suas diferentes formas, dimensões $\mathrm{e}$ práticas, como referíamos no início deste artigo. Compensando a procura do "grande retrato" sobre o que é jornalismo, que tem sido norma da pesquisa sob as lentes da Sociologia e da Ciência Politica, a análise cultural acentua precisamente a diversidade do que constitui noticia e jornalismo, explora a dissonância estratégica entre o que o jornalismo diz ser e como se apresenta, considera as convenções $e$ as rotinas jornalísticas como dinâmicas e contingentes.

Algumas das linhas trabalhadas pela pesquisa cultural podem ser pertinentes para o estudo da noticiabilidade da infância. Entre os pontos da sua agenda para o estudo do jornalismo, sistematizados por Zelizer (2004), destacamos as visões do mundo por parte dos jornalistas, as suas práticas, formatos e audiencias.

1. A atenção às visões do mundo do jornalismo incide no "quadro

mental" colectivo dos jornalistas, como se pensam como jornalistas e como pensam o mundo à sua volta, como agem nos seus desempenhos profissionais. Entra também aqui a atenção aos índices exteriores de "identidade", como o gênero, a etnia, a idade, a orientação sexual.

O cruzamento da variável gênero com a identidade profissional tem permanecido relativamente secundário nos estudos sobre o jornalismo e estas notícias podem ser uma via para a sua pesquisa. A pesquisa longitudinal atrás apresentada deu conta, nos anos 90 , de uma maior assinatura feminina nas peças sobre crianças, associável à feminização da profissão, com notória subida das mulheres nas redacções nos últimos anos. A atribuição destas matérias a jornalistas mulheres é também destacada nos estudos norteamericanos, colocando imaginários de notícia e de profissão que lhes atribuem o tratamento preferencial de matérias da esfera privada, da ordem dos "cuidados". Nas palavras de um jornalista português, reflectindo sobre essa divisão:

"É engraçado... sobre as crianças. Se o assunto é o trabalho infantil ou a criminalidade, se é informação hard, temos um jornalista a cobrir. Se é sobre a paternidade, as disfunções sociais da familia, se 
é soft, temos uma jornalista. Não é deliberado, não é mesmo, mas acaba por ser assim quando pensamos nisso. É dificil sair dai..."

No estudo de Goonsekera, impera um imaginário comum de notícia, que reproduz a cultura jornalística dominante, centrada na neutralidade da intervenção. A noticiabilidade dessas matérias é expressa em termos de faro jornalístico e de orientação para a noticiabilidade como coisa, num ideal de imparcialidade e objectividade factual e por uma confiança em saber decidir o que interessa ou não aos seus leitores:

"Qualquer matéria é escrita como noticia se se considera que contém informação e que pode educar o povo sobre o que acontece na sociedade. As noticias sobre crimes e acidentes interessam muito as pessoas e se se fala de crianças é porque crianças estão envolvidas nesses casos" (Editor de jornal da Malásia);

"O foco é a noticiabilidade e se isso inclui crianças então elas são noticia" (Editor de Singapura);

"Sobre os problemas das crianças do Paquistão não sabemos se a nossa cobertura é adequada ou não. Na verdade não há certezas no jornalismo. Escrevemos e editamos e é essa a nossa tarefa. O resto depende do que as pessoas com poder no pais possam fazer." (Mulher jornalista paquistanesa).

Pretendemos dar relevo a esta variável, através da atenção a quem assina as peças, aos estilos de recolha e de tratamento, e discutir os resultados recolhidos e as rotinas profissionais activadas nessa cobertura, com jornalistas e editores.

2. As práticas do jornalismo reúnem nomeadamente as modalidades activadas em coberturas noticiosas de diferentes temáticas, os modos como são construídas as aproximações dos jornalistas a temas e histórias.

Sobre este ponto, é interessante ter presente o contraste que John Hartley (1998: 62) estabelece entre as quatro meta-narrativas clássicas que organizam as noticias (conflito, progresso, disputa e acidentes) e metanarrativas pós modernas, fora desse quadro de negatividade e de criação de adversários. Essas meta-narrativas são constituídas por: 1) Homílias seculares (conhecimentos úteis sob a forma semiótica do sermão, transmitindo conselhos pessoais ou éticos, para uso pessoal, familiar e melhor desempenho social; 2) Histórias cordiais (que promovem uma formação sobre os direitos em vez de um catálogo sobre "anomalias" e "acidentes"); 3) Uma esfera 
privada (onde o leitor é interpelado como um consumidor/cliente que procura entreter-se e satisfazer os seus desejos, e não como um cidadão soberano que procura informação para tomada de decisões políticas; 4) Identificação (peças sobre estilos de vida não ameaçadores, centrados na comunidade do nós, não nos outros).

Narrativas modernas e pós-modernas podem coexistir nos mesmos jornais, variando segundo os temas. Como nota Schudson (2000: 193-4):

"Repórteres que aderem às normas da objectividade quando cobrem uma campanha politica não evitam reportar de forma solene um tópico sobre o qual exista um grande consenso nacional ou escrever de forma depreciativa sobre um assunto que fique de fora do consenso popular. É como se os jornalistas falassem, de forma não consciente, diferentes linguas, passando de intérpretes neutrais a guardiães do consenso social e de novo regressarem à neutralidade, sem falharem um lugar".

Esta variação nos códigos está claramente presente nas notícias sobre crianças e jovens. Articulando as narrativas modernas e pós-modernas com a atenção às audiências construídas, Hartley (1998: 51-2, destaques seus) apresenta três grandes pontos para a crescente referência a crianças nas notícias:

1. Os media noticiosos usam a juvenilização de forma positiva como parte indispensável da sua estratégia de convocação de audiências $e$ de leitores. As crianças são o condutor semiótico da visualização do reino do nós (Wedom no original). A juvenilização é uma estratégica comunicativa estrategicamente traçada para olear os trabalhos do jornalismo.

2. Ao mesmo tempo, os media noticiosos mantêm os valores centrais das hard news, da negatividade e da procura da verdade, nas histórias sobre os mais novos. As crianças estão a ser cada vez mais sujeito das mesmas tácticas de relato negativo que abrange os adultos, sobretudo em histórias sobre a indisciplina e a rebeldia (de rapazes) ou de sexualidade (raparigas). As crianças são o "fair game" como alvo noticioso de um modo impensável anos atrás. Assim, enquanto se tornam mais visiveis nas noticias como metáforas juvenilizadas do Wedom, são também mais colocadas fora desse espaço, num movimento semiótico que se apropria do seu aspecto para as exigências da noticia como sistema textual, mas que exclui as suas aç̧ões, não apenas as ameaçadoras ou vulneráveis, mas porque as considera fora das fronteiras do social. 
3. As noticias sobre crianças são quase sempre sobre algo mais. A explicação para a intensidade da cobertura em qualquer instância decorre da esfera dos media, não da natureza do evento. As histórias com maior destaque tendem a focar-se em questões que não são de importância fundamental para as crianças, enquanto as histórias de importância capital tendem a ser relativamente desvalorizadas. $A$ atenção foca-se em epifenômenos ou na demonização de sujeitos "diabólicos", em vez de se centrar nos cuidados e recuperação das crianças envolvidas.

O sentimentalismo e dramatismo associado a crianças como vítimas na cobertura noticiosa internacional são também sublinhados por Moeller (2002:39):

"A imagem de uma criança em perigo é um 'isco' perfeito. É tão forte que impede o pensamento racional. As crianças acentuam a dramaticidade de uma causa ao ser contrastada a sua inocência com a malevolência (ou talvez apenas a banal hostilidade) de adultos com poder. Por fim, ofoco nas crianças serve uma função logistica. Uma vez que há crianças em todo o mundo, estão sempre disponiveis, e depressa, para servirem de cabide noticioso."

18 Neste contexto, é nosso objectivo, para além da pesquisa quantitativa, prestar uma especial atenção à cobertura noticiosa de actos de delinquência, da educação na perspectiva do aluno e das culturas a que são associados crianças e jovens, através de metodologias qualitativas de análise.

3. A atenção aos formatos do jornalismo incide, entre outras, nas formas de apresentação das notícias em imprensa, rádio e televisão, a formas alternativas de jornalismo, orientadas para questões de interesse público e de cidadania informada è participada.

A atenção além dos "jornais de referência" tem suscitado pesquisa sobre como é que as formas de jornalismo popular preenchem funções deixadas em aberto por aqueles (Sparks e Tulloch, 2000). O binômio qualidade/ popular apresenta importantes variações de país para país e que em certos países tem mais sentido apreciar a imprensa segundo um continuum de variação entre o máximo de centragem na esfera pública e em temas da esfera da economia, das questões de sociedade e da política (que poderia ser chamado de Jornal de Registos), por um lado, e de centragem na esfera privada e na atenção exclusiva a temas de entretenimento, espectáculos e desporto (o Verdadeiro Tabloide), por outro, escreve Sparks-(2000: 12), sublinhando que nenhum destes jornais existe em absoluto. 
4. Por fim, a atenção às audiências do jornalismo parte do reconhecimento de que o jornalismo actua de modos diferentes de acordo com as identidades da sua audiência. O cruzamento desse aspecto com as práticas do jornalismo foi salientado nas palavras de Hartley, atrás apresentadas.

As pesquisas de audiência realizadas sob este prisma cultural diferenciam-se do inquérito sociológico, prestando atenção a processos de leitura de jornais e de socialização primária, às variáveis gênero, idade e etnia na recepção da informação.

Resultados eleitorais recentes em paises europeus mostram que uma percentagem significativa de jovens prescinde de exercer o seu direito de voto, como cidadão. Um baixo nivel de interesse pela vida pública pode ter muito a ver com perspectivas estreitas do que é a cidadania. Tem também a ver com o lugar exterior à sociedade em que são colocadas crianças $e$ adolescentes, fora do mundo dos adultos, sem voz nem capacidade de exprimirem as suas experiências, sentimentos e perspectivas. Esta idéia pode ser ilustrada pela falta de recursos informacionais dirigidos a audiências dos mais novos, por parte das organizaçðes mediáticas, nomeadamente de serviço público, na tradição européia ocidental, como faz notar Buckingham (2000), que assinala o desaparecimento de conteúdos informativos nos programas televisivos para crianças.

Da perspectiva das sociedades democráticas contemporâneas, contudo, sublinham Carter e Allan (2005), é importante que os mais novos se sintam conectados de forma activa com os eventos que ocorrem à sua volta, que sintam que as suas vozes são ouvidas. Não só devem ser estimulados a participar nas decisões públicas como as suas opiniões devem ser tidas em conta.

\section{5: Crianças e adolescentes nas noticias}

Na sequência da pesquisa realizada sobre a imprensa portuguesa, estamos actualmente realizar o projecto Crianças e A dolescentes nas Noticias, que muito deve em inspiração também ao trabalho inspirador da ANDI, sendo nosso propósito trabalhar indicadores que permitam comparar resultados quantitativos e qualitativos.

$\mathrm{Na}$ actualização e ampliação da pesquisa anterior, destacamos a importância à variável gênero na profissão, o alargamento dos meios agora sob análise (jornais populares, noticiários televisivos), a relação com jornalistas e organizações no terreno, bem como a auscultação a crianças e jovens sobre como se vêem representados nas notícias.

São assim objectivos deste Projecto: 
1. Actualizar a análise às notícias sobre crianças publicadas no Público e no Diário de Notícias, 5 anos depois do último estudo comparado; 2. Comparar as agendas noticiosas dos jornais de qualidade e de jornais populares;

3. Comparar as agendas noticiosas da televisão generalista com as da imprensa;

4. Analisar qualitativamente o tratamento jornalístico da Educação, de temas de Justiça associados a crianças e adolescentes e da Cultura de crianças e adolescentes;

5. Analisar processos comunicativos de fontes de informação associadas à defesa dos direitos das crianças;

6. Pesquisar como diferentes grupos etários (6-10 anos; 13-17 anos) e crianças institucionalizadas apreciam notícias que as envolvem

7. Organizar Oficinas para profissionais dos media e de sectores com intervenção neste campo (profissionais de educação, de assistência social, ONG etc.), a fim de promover maior conhecimento mútuo.

8. Socializar resultados das investigações e alargar o debater.

\section{Sintese final}

Traçamos neste artigo contributos da pesquisa sobre as notícias incidindo sobre crianças, sublinhando as características contraditórias dos seus conteúdos e a necessidade de uma atenção a narrativas, formatos, audiências e práticas jornalísticas para além das balizas clássicas da investigação jornalística.

No conjunto destes estudos, podemos identificar diferentes tipos de discursos noticiosos sobre crianças e infância, entre o texto das hard news, notícias de conflitos, de casos em disputa, acidentes e polêmicas de final incerto, por um lado, e histórias cordiais e de aconselhamento, orientadas para a experiência privada dos leitores, como progenitores, focadas nas "nossas crianças" e nas preocupações com o seu bem-estar, por outro. Há lógicas sobrepostas: a lógica da notícia como facto e a sua retórica da factualidade, sem questionar que factos estão sistematicamente ausentes e porquê; a lógica do "jornal total", combinando informação dramatizada de forma sensacionalista com conteúdos informativos ligeiros e de entretenimento; a lógica de um jornalismo de comprometimento, militante nas suas campanhas e cruzadas, como aconteceu na imprensa norte-americana em 1993, algumas de forte pendor moralista, ou um jornalismo cívico, alargando os tópicos e as vozes das notícias e avaliando-as na base dos direitos de cidadania, como tem vindo a ser incentivado pelo trabalho da ANDI no Brasil, e em expansão na América Latina. 


\section{Referências bibliográficas}

Buhler-Niederberger, D. (1999). The Public Image of Children in Recent Electoral Campaigns. Kamla-Raj Enterprises, 3(1-2), 11-20.

Buhler-Niederberger, D., \& Hungerland, B. (1997, May 30-June 2). The Social Value of Children - and the Sociology of its Assessement Process. Conference on Childhood and Children's Culture, Esbjerb, Denmark.

Buckingham, D. (2000). The Making of Citizens. Young People, News and Politics. London, Routledge.

Carey, J. (1975). The Problcm of Journalism History. In E. Munson \& C. Warrens (Eds.), James Carey: a Critical Reader (pp. 79-94). University of Minnesota Press, 1997.

Carlsson, U., \& Feilitzen, C. v. (Eds.). (1998). Children and Media Violence: UNESCO International Clearinghouse on Children and Violence on the Screen. Carter, C. and S. Allan (2005). Young people's voices: Citizenship, media education and online news. Communication in Adolescence: Perspectives on language and social interaction in the teenage years. A. Williams and C. Thurlow. London, Peter Lang

Goonasekera, A., Ed. (2001). Children in the News: An Examination of the Portrayal of Children in Television and Newspapers in 13 Asian Countries. Singapore, Asian Mass Communication Research and Information Centre. Hallin, D. C. (1996). Commercialism and Professionalism in the American News Media. Mass Media and Society. J. Curran e M. Gurevitch. London, Edward Amold: 243-264.

Hartley, J. (1998). Juvenation: News, Girls and Power, News, Gender and Power. C. Carter, G. Branston and S. Allan. London, Routledge: 47-70.

Hughes, H. (1940). News and Human Interest Story. New Brunswick, Transaction Books.

James, A., \& Jenks, C. (1996). Public Perceptions of Childhood Criminality. British Journal of Sociology, 47(2), 315-331.

Jempson, M. (2003). Children and media - a global concern.

Kitzinger, J. (1999). The Ultimate Neighbour from Hell? Social Policy, the Media and Misrepresentation. B. Franklin. London, Routlege: 207-221. 
Kitzinger, J. (2004). Framing Abuse. Media influence and public understanding of sexual violence against children. London: Pluto Press. Kunkel, D. (1996). The News Media's Picture of Children. Internet Explorer, Children Now.

Kunkel, D., E. Rollin, et al. (1999). The News Media's Picture of Children: a Five Year Update and a Focus on Diversity. Seatle, Children Now.

Moeller, S. (2002). "A Hierarchy of Innocence. The Media's Use of Children in the Telling of International News." Press/Politics 7(1): 36-56.

Ponte, C. (2005). Crianças em noticia. A construção da infância pelo discurso jornalistico (1970-2000). Lisboa, Imprensa de Ciências Sociais.

Schudson, M. (2000). The Sociology of News Production Revisited (Again). Mass Media and Society. J. Curran and M. Gurevitch. London, Arnold: 175200.

Skidmore, P. (1998). Gender and Agenda: News Reporting of Child Sexual Abuse. In C. Carter, G. Branston \& S. Allan (Eds.), News, Gender and Power (pp. 204-218). Londres: Routledge.

22 Sparks, C: (2000). Introduction. The Panic over Tabloid News. In C. Sparks \& J. Tulloch (Eds.), Tabloid Tales (pp. 1-40). New York: Rowman \& Littlefield publishers.

Sparks, C., \& Tulloch, J. (Eds.). (2000). Tabloid Tales: Global Debates over Media Standards. New York: Rowman \& Littlefield Publishers.

Trost, C. (1996). From Unseen and Unheard to Kidsbeat. Children and the Media. E. Dennis and E. C. Pease. New Brunswick, Transaction Publishers Zelizer, B. (2004). Taking Journalism Seriously. Thousand Oaks, Sage 